\title{
Amazonian Robustas - new Coffea canephora coffee cultivars for the Western Brazilian Amazon
}

Crop Breeding and Applied Biotechnology 20(3): e323420318, 2020 Brazilian Society of Plant Breeding. Printed in Brazil http://dx.doi.org/10.1590/1984$70332020 v 20 n 3 c 53$

\section{Alexsandro Lara Teixeira ${ }^{{ }^{*}}$, Rodrigo Barros Rocha ${ }^{1}$, Marcelo Curitiba Espindula ${ }^{1}$, André Rostand Ramalho ${ }^{1}$, José Roberto Vieira Júnior ${ }^{2}$, Enrique Anastácio Alves ${ }^{1}$, Aureny Maria Pereira Lunz $^{3}$, Flávio de França Souza ${ }^{4}$, José Nilton Medeiros Costa ${ }^{1}$ and Cleberson de Freitas Fernandes ${ }^{2}$}

\begin{abstract}
Amazonian Robustas are ten new clones of high yield potential with characteristics typical of the botanical varieties conilon and robusta. With individual registration, the new cultivars were developed to be grown together with other clones, with flexibility of composition of the crops according to the preference of the producer.
\end{abstract}

Keywords: Coffea canephora, Western Amazon, conilon x robusta hybrids.

\section{INTRODUCTION}

Coffee production in the state of Rondônia (RO) developed from the cultivation of $C$. canephora plants with characteristics of the botanical varieties conilon and robusta. The conilon botanical variety is distinguished by its small size, greater tolerance to water stress, and less resistance to coffee leaf rust (Hemileia vastatrix). In turn, the robusta botanical variety has greater resistance to rust and to root-knot nematode (Meloidogyne spp.), fruit with greater potential for preparing specialty coffee beverages, and taller plants that are less tolerant to water stress (Charrier and Eskes 2004). From the natural or directed breeding of plants of these two botanical varieties, hybrid plants appear, which can combine the best characteristics of the two varieties (Rocha et al. 2015, Oliveira et al. 2018).

In order to offer new options for growers and increase the genetic variability of coffee in the Western Amazon, Embrapa Rondônia has developed ten new cultivars with high yield potential and agronomic characteristics typical of the conilon and robusta botanical varieties.

The development of these cultivars is the result of 16 years of research, initiated in 2003 with controlled hybridization between parent plants of the conilon and robusta varieties from the Embrapa Active Germplasm Bank (Souza et al. 2013). The most notable advances obtained from development of these cultivars include the following: the individual clone record, the hybrid nature of the cultivars, and the wealth of information on each cultivar.

With individual registration, the new cultivars were developed for growing together with other clones and flexibility of crop composition based on growers'
*Corresponding author: E-mail: alexsandro.teixeira@embrapa.br (D) ORCID: 0000-0003-1125-7082

Received: 12 May 2020 Accepted: 03 August 2020 Published: 25 September 2020

\footnotetext{
${ }^{1}$ Embrapa Rondônia, BR 364, 76.815-800, Porto Velho, RO, Brazil

2 Embrapa Agroindústria Tropical, Rua Dra. Sara Mesquita, 60.511-110, Fortaleza, CE, Brazil

${ }^{3}$ Embrapa Acre, BR 364, 69.900-970, Rio Branco, AC, Brazil

${ }^{4}$ Embrapa Semiárido, BR 428, 56.302-970, Petrolina, PE, Brazil
} 


\section{AL Teixeira et al.}

preferences. To that end, evaluations of yield potential, resistance to pests and diseases, beverage quality, plant spacing, management practices, and compatibility between clones were considered.

As a result of their hybrid nature, the best characteristics of the conilon and robusta botanical varieties are expressed, associated with the greater vigor of the hybrid plants. The intermediate size, resistance to rust $(H$. vastatrix) and nematodes (Meloidogyne incognita - EI2), and the potential for higher beverage quality are some of the characteristics observed in the cultivars.

The information obtained on the new cultivars is the result of experiments carried out in different environments, in the field, greenhouse, and laboratory, considering specific crop traits, such as yield, compatibility, response to biotic stresses, and beverage quality.

\section{METHODS}

The name of each cultivar consists of the acronym BRS, which begins the name of cultivars released by Embrapa, and four numerical digits that express the compatibility group, the maturation cycle, and the cultivar identification number (Table 1). The first digit identifies the compatibility group to which the clone belongs, which can be one (1), two (2), or three (3). The second digit refers to the maturation cycle, differentiating early, intermediate, and late, identified respectively by the numbers one (1), two (2), and three (3). The last two digits are the cultivar identification number (Table 1). Thus, clone 1216 (read twelve, sixteen) is part of compatibility group 1, has an intermediate maturation cycle, and its identification number is 16 (sixteen).

The new cultivars were developed by breeding plants of the botanical varieties conilon and robusta. Hybridizations were carried out in 2003 in the experimental field at Embrapa Rondônia using parent plants of the botanical variety robusta (IAC 2258, IAC 1675, IAC 640) and a parent plant of the botanical variety conilon (Emcapa 03, pollen grain donor plant) (Table 2). From 2003 to 2010, these plants were evaluated in trials in the municipality of Ouro Preto do Oeste, RO, and selected for evaluation in different environments together with clones from open pollination. The open-pollinated cultivars BRS 2299 and BRS 2357 were selected in the conilon cultivar BRS Ouro Preto, developed by Embrapa in 2013 (Ramalho et al. 2016).

\section{PERFORMANCE CHARACTERISTICS}

\section{Yield}

Yield is affected both by plant yield potential and by environmental conditions, such as climate, soil, and management techniques (Fonseca et al. 2004, Partelli et al. 2019, Moraes et al. 2020). Although all cultivars have a yield potential greater than 100 bags per hectare, there is genetic variability among the selected plants, which supports their classification in three distinct categories. The cultivars BRS 1216, BRS 2336, BRS 3210, and BRS 3213 have the greatest yield potential, an average of 80.75 bags ha $^{-1}$ over three years, evaluated in four environments in the states of Rondônia and Acre (Table 3).

Table 1. List of the names of ten $C$. canephora coffee cultivars with specification of the compatibility group, the maturation cycle, and the identification number of the cultivar

\begin{tabular}{lcccc}
\hline Cultivar & Compatibility group & Maturation cycle & ID of the cultivar & Pronunciation \\
\hline BRS 1216 & 1 & 2 & 16 & Twelve - sixteen \\
BRS 2299 & 2 & 2 & 99 & Twenty-two - ninety-nine \\
BRS 2314 & 2 & 3 & 14 & Twenty-three - fourteen \\
BRS 2336 & 2 & 3 & 36 & Twenty-three - thirty-six \\
BRS 2357 & 2 & 3 & 57 & Twenty-three - fifty-seven \\
BRS 3137 & 3 & 1 & 37 & Thirty-one - thirty-seven \\
BRS 3193 & 3 & 1 & 93 & Thirty-one - ninety-three \\
BRS 3210 & 3 & 10 & Thirty two - ten \\
BRS 3213 & 3 & 13 & Thirty-two - thirteen \\
BRS 3220 & 3 & 2 & 20 & Thirty two - twenty \\
\hline
\end{tabular}


The cultivars BRS 2299, BRS 3137, and BRS 3220 have potential yield of more than 110 bags of processed coffee, with an average of 66.00 bags ha $^{-1}$ over three years, evaluated in four environments in the states of Rondônia and Acre (Table 3). The cultivars BRS 2314, BRS 2357, and BRS 3193 have potential yield of more than 100 bags of processed coffee, with an average of 61 bags ha ${ }^{-1}$ over three years (Table 3 ).

\section{Compatibility between cultivars}

Fruit production of $C$. canephora coffee depends on pollination between compatible plants. The impossibility of pollination between incompatible clones is a trait of this species of great importance for clonal cultivation (Rocha et al. 2013, Ferrão et al. 2017). Two plants are considered compatible when they are clustered in different compatibility groups. Although in the African continent, the center of origin of this species, six distinct compatibility groups have been reported, in Brazilian coffee plantations only three compatibility groups have been observed (Moraes et al. 2018). Based on targeted pollinations and fluorescence microscopy, the clones under evaluation were clustered into three different compatibility groups (Table 1).

To increase pollination efficiency, the use of pollinator lines or the cultivation of a minimum number of clones is considered. Technically, the cultivation of six clones, two from each compatibility group, in equal proportions, provides good pollination efficiency. However, when clone compatibility is not known, cultivating around nine clones is recommended to achieve high pollination efficiency.

\section{Responses to biotic stresses}

Each cultivar has its own characteristics, reflected in different responses of resistance to the main coffee diseases. When choosing the best genotypes to form a coffee plantation, it is important to consider that there is no perfect cultivar that brings together all the desired characteristics and has a superior response in all environments. Thus, the selection of cultivars must take into account the intended management conditions.

Currently, the diseases that most damage coffee crops in Brazil are coffee leaf rust, caused by Hemileia vastatrix, and root-knot nematode, caused by species of the genus Meloidogyne. Less aggressive and of difficult diagnosis, Meloidogyne exigua is the most widespread species that causes damage to Coffea arabica plants. The species Meloidogyne incognita - El2 has occurred most in C. canephora cultivation in the state of Rondônia (Santos et al. 2018).

Table 3. Average yield of ten coffee cultivars $C$. canephora over three years, evaluated in the environments of Rio Branco, Acre (RBAC); Ouro Preto do Oeste, Rondônia (OPO-RO); Porto Velho, Rondônia (PV-RO); and Alta Floresta D'Oeste, Rondônia (AFO-RO), Brazil

\begin{tabular}{|c|c|c|c|c|c|c|c|}
\hline Cultivar & RB-AC & OPO-RO & PV-RO & AFO-RO & Average $^{1}$ & Maximum $^{2}$ & Category $^{3}$ \\
\hline BRS 1216 & $70.09 a$ & $76.58 a$ & $88.67 a$ & $106.47 a$ & $85.45 a$ & 122 & 1 \\
\hline BRS 2336 & $68.40 a$ & $78.33 a$ & $75.04 a$ & $101.07 a$ & $80.71 a$ & 123 & 1 \\
\hline BRS 3210 & $66.36 a$ & $80.20 a$ & $60.95 b$ & $111.41 a$ & $79.73 a$ & 133 & 1 \\
\hline BRS 3213 & $67.20 a$ & $76.89 a$ & $71.15 a$ & $91.01 b$ & $76.56 a$ & 120 & 1 \\
\hline BRS 2299 & $70.17 a$ & $43.88 b$ & $69.85 a$ & $87.34 b$ & $67.81 \mathrm{~b}$ & 112 & 2 \\
\hline BRS 3137 & $65.35 a$ & $49.06 b$ & $63.21 b$ & $87.35 b$ & $66.24 b$ & 110 & 2 \\
\hline BRS 2357 & $61.18 b$ & $43.35 b$ & $57.19 b$ & $83.32 b$ & $61.26 \mathrm{~b}$ & 107 & 3 \\
\hline BRS 3193 & $52.58 b$ & $42.41 b$ & $43.40 \mathrm{~b}$ & $78.69 b$ & $54.27 c$ & 107 & 3 \\
\hline
\end{tabular}

${ }^{1}$ Average yield in bags of hulled coffee from cultivars in 4 environments in the states of Rondônia and Acre; ${ }^{2}$ Maximum yield observed in the year of best plant development; ${ }^{3}$ Categories according to the yield potential of the cultivars. Mean values identified by the same letter in the column belong to the same cluster according to the Scott-Knott test at $5 \%$ probability. 
Assessments carried out over a three-year period, in the field and greenhouse, were interpreted to determine manifestation of rust resistance. Less than $1 \%$ diseased plants in a population characterize resistant clones, whereas higher percentages characterize susceptible clones (Table 4).

The resistance response to nematodes was evaluated based on tests conducted in a greenhouse in Porto Velho and Ji-Paraná, RO. Clones considered susceptible through observation showed root knots, eggs, and juveniles of the nematode in the roots exceeding the established standards (Santos et al. 2018). When choosing clones for planting, care should be taken when using clones considered to be very susceptible in areas whose history indicates high nematode infestation (Table 4).
Table 4. Resistance response to coffee leaf rust, caused by $H$. vastatrix, and root-knot nematode ( $M$. incognita - El2) of ten $C$. canephora coffee cultivars, classified according to their resistance or susceptibility to the action of pathogens

\begin{tabular}{lccccc}
\hline \multirow{2}{*}{ Cultivar } & \multicolumn{2}{c}{ Rust } & & \multicolumn{2}{c}{ Nematode } \\
\cline { 2 - 3 } \cline { 5 - 6 } & Code & Reply & & Code & Reply \\
\hline BRS 1216 & R & Resistant & & XR & Very resistant \\
BRS 2299 & R & Resistant & & R & Resistant \\
BRS 2314 & R & Resistant & & XR & Very resistant \\
BRS 2336 & R & Resistant & & SS & Very susceptible \\
BRS 2357 & S & Susceptible & & SS & Very susceptible \\
BRS 3137 & R & Resistant & & R & Resistant \\
BRS 3193 & R & Resistant & & SS & Very susceptible \\
BRS 3210 & R & Resistant & & XR & Very resistant \\
BRS 3213 & R & Resistant & & MR & Moderately resistant \\
BRS 3220 & R & Resistant & & S & Susceptible \\
\hline
\end{tabular}

\section{Beverage quality}

For a long time, $C$. canephora beans were used only for blends with arabica coffee beans. However, more recently, the beverage quality of the beans from this coffee tree has been appreciated for aroma and flavor traits: less sweetness, less acidity, and greater bitterness (Souza et al. 2018). According to the Fine Robusta protocol, the main organoleptic attributes for evaluation of the Canephora species are aroma, flavor, aftertaste, salt/acidity ratio, bitterness/sweetness ratio, mouth-feel, cup balance, uniformity, cleanness, and overall aspects. The average score for each attribute is used to obtain a final score, which ranges from 0 to 100 , and classifies the beverage according to its quality.

Among the ten new hybrid cultivars recommended for cultivation in the Amazon region, the BRS 2314 cultivar is noteworthy. According to the Fine Robusta cupping protocol, it had an average score of 83.8, ranging from 80 to 87.2 points in different environments of the states of Rondônia and Acre. The main characteristics of its beverage are sweetness and a chocolate flavor. It also has nuances of citrus fruits and almonds, creating a balanced mixture with pleasant acidity.

The BRS 1216 and BRS 3220 cultivars are noteworthy for their potential to produce coffee beans with specialty coffee quality. The BRS 1216 cultivar achieved an average score of 79.6 points, ranging from 78.3 to 80 points; it has medium sweetness, with chocolate flavor and aroma. The BRS 3220 cultivar, in turn, created a beverage with a combination of almond and pepper flavors and brief aftertaste. It obtained an average score of 79.1, ranging from 76 to 82 points.

The other cultivars have beverage quality considered good, without prominent beverage attributes (Table 5). In general, they have neutral beverages, low sweetness, and discreet aroma, attributes that are valued by the soluble coffee industry and for composition of blends with arabica.

Table 5. The main beverage quality attributes of ten $C$. canephora coffee cultivars, evaluated in five environments in the states of Rondônia and Acre, Brazil

\begin{tabular}{|c|c|c|c|c|}
\hline Cultivar & $\begin{array}{l}\begin{array}{l}\text { Average } \\
\text { sieve }^{1}\end{array} \\
\end{array}$ & Maturation cycle ${ }^{2}$ & Beverage quality ${ }^{3}$ & Attributes $^{4}$ \\
\hline BRS 1216 & 15 & Intermediate & $>79$ points (specialty potential) & Chocolate, cereal, woody \\
\hline BRS 2299 & 14 & Intermediate & $>70$ points (good commercial) & Neutral, cereal, herbal \\
\hline BRS 2336 & 16 & Late & $>75$ points (good commercial) & Sweet, smooth aftertaste \\
\hline BRS 2357 & 15 & Late & $>70$ points (good commercial) & Neutral, no prominent attributes \\
\hline BRS 3137 & 14 & Early & $>70$ points (good commercial) & Neutral, no prominent attributes \\
\hline BRS 3210 & 16 & Intermediate & $>70$ points (good commercial) & Neutral cereal \\
\hline BRS 3213 & 15 & Intermediate & $>75$ points (good commercial) & Woody, herbal, spicy \\
\hline BRS 3220 & 15 & Intermediate & $>79$ points (specialty potential) & Almonds, pepper, dry finish \\
\hline
\end{tabular}

${ }^{1}$ Average sieve: average flat grain size measured according to a set of sieves ranging from 13 to $18 .{ }^{2}$ Maturation cycle: Period required for fruit ripening, classified as early, intermediate, and late according to the cultivars that ripen in the months of April, May, and June, respectively. ${ }^{3}$ Beverage quality: final score according to the Fine Robusta Cupping Protocol (FRCP), ${ }^{4}$ Attributes: predominant characteristics observed in the beverage. 


\section{Foundation seed production}

A Basic Plant Field is maintained by Embrapa at its Experimental Station in Ouro Preto do Oeste (lat 10 43' 55" S, long 62 15' 19" W, alt $237 \mathrm{~m}$ asl), RO, which serves as a repository for the cultivars. Cuttings (vegetative propagules) from the basic plant field were made available to private nurseries, associations, and public institutions through a partnership contract established between the interested party and Embrapa. Currently, 11 nurseries have authorization for commercial production, ten in the state of Rondônia and one in the state of Amazonas, and 30 observation units have been established in ten other states of Brazil, including all its regions.

\section{REFERENCES}

Charrier A and Eskes AB (2004) Botany and Genetics of Coffee. In Wintgens JN (ed) Coffee: Growing, processing, sustainable production. WileyVCH, Darmstadt, p. 25-56.

Ferrão MAG, Souza EMR, Fonseca AFA and Ferrão RG (2017) Autoincompatibilidade e produção sustentável do café Conilon. In Ferrão RG, Fonseca AFA, Ferrão MAG and Muner LH (ed) Café Conilon. $2^{\text {sd }}$ edn, Incaper, Vitória, p.177-191.

Fonseca AFA, Ferrão MAG, Ferrão RG, Filho ACV, Volpi OS and Zucateli F (2004) 'Conilon Vitória - Incaper 8142': improved Coffea canephora var. kouillou clone cultivar for the state of Espírito Santo. Crop Breeding and Applied Biotechnology 4: 503-505.

Moraes MS, Teixeira AL, Ramalho AR, Espindula MC, Ferrão MAG and Rocha RB (2018) Characterization of gametophytic selfincompatibility of superior clones of Coffea canephora. Genetics and Molecular Research 17: 1-11.

Moraes MS, Rocha RB, Teixeira AL, Espindula MC, Silva CA and Lunz AMP (2020) Adaptability and stability of Coffea canephora Pierre ex Froehner genotypes in the Western Amazon. Ciência Rural 50: 1-10.

Oliveira LNL, Rocha RB, Ferreira FM, Spinelli VM, Ramalho AR and Teixeira AL (2018) Selection of Coffea canephora parents from the botanical varieties Conilon and Robusta for the production of intervarietal hybrids. Ciência Rural 48: 1-7.

Partelli FL, Golynski A, Ferreira A, Martins MQ, Mauri AL, Ramalho JC and
Vieira HD (2019) Andina - first clonal cultivar of high-altitude conilon coffee. Crop Breeding and Applied Biotechnology 19: 476-480.

Ramalho AR, Rocha RB, Souza FF, Veneziano W and Teixeira AL (2016) Progresso genético da produtividade de café beneficiado com a seleção de clones de cafeeiro Conilon. Revista Ciência Agronômica 47: 516-523.

Rocha RB, Teixeira AL, Ramalho AR and Souza FF (2015) Melhoramento de Coffea canephora: considerações e metodologias. In Marcolan AL and Espindula MC (ed) Café na Amazônia. Embrapa, Porto Velho, p. 101-126.

Rocha RB, Santos DV, Ramalho AR and Teixeira AL (2013) Caracterização e uso da variabilidade genética de banco ativo de germoplasma de Coffea canephora Pierre ex Froehner. Coffee Science 8: 478-485.

Santos AV, Rocha RB, Silveira SF, Teixeira AL, Matos SI and Vieira Júnior JR (2018) Characterization of resistance response of Coffea canephora genotypes to Meloiddogyne incognita (Est I2) root-knot nematode. Coffee Science 13: 219-229.

Souza FF, Caixeta ET, Ferrão LFV, Pena GF, Sakiyama NS, Zambolim EM, Zambolim L and Cruz CD (2013) Molecular diversity in Coffea canephora germplasm conserved and cultivated in Brazil. Crop Breeding and Applied Biotechnology 13: 221-227.

Souza CA, Rocha RB, Alves EA, Teixeira AL, Dalazen JR and Fonseca AFA (2018) Characterization of beverage quality in Coffea canephora Pierre ex A. Froehner. Coffee Science 13: 210-218. 